\title{
Cyclooxygenase-2 promotes tumor growth and suppresses tumor immunity
}

Bing Liu', Liyan Qu ${ }^{2,3}$ and Shigui Yan ${ }^{1 *}$

\begin{abstract}
Cyclooxygenase-2 (COX-2), an inducible form of the enzyme that catalyzes the first step in the synthesis of prostanoids, is associated with inflammatory diseases and carcinogenesis, which is suspected to promote angiogenesis and tissue invasion of tumors and resistance to apoptosis. Meanwhile, COX-2 contributes to immune evasion and resistance to cancer immunotherapy, which plays a crucial role in the innate and adaptive immune response. The activity of COX-2-PGE2-EP signal pathway can suppress Dendritic cells (DCs), natural killer (NK), T cells, type-1 immunity excluding type-2 immunity which promote tumor immune evasion. COX-2 and the prostaglandin cascade play important roles in the "inflammogenesis of cancer". In addition, COX-inhibitors can inhibit tumor immune evasion. Therefore, we can exert the COX-inhibitors to facilitate the patients to benefit from addition of COX-inhibitors to standard cytotoxic therapy.
\end{abstract}

Keywords: COX-2, COX-inhibitors, EP, Innate immunity, Adaptive immunity

\section{Background}

Human malignancies generally arise as the culmination of a multistep process that involves various somatic gene alterations. Therefore, we can exert the drug to affect over-expressed or low-expressed genes and achieve the therapies of human malignancies. It was learned that COX-2 is overexpressed in most solid tumors such as colorectal, liver, pancreatic, breast as well as lung cancer [1-6]. Both non-selective non-steroidal anti-inflammatory drugs (NSAIDs) and selective COX-2 inhibitors can inhibit proliferation, tumors invasiveness and angiogenesis, and at the same time overcome apoptosis and drug resistance as well as suppress of immune responses. Immune responses include innate immunity and adaptive immunity. Tumor-associated immune responses can be generalized to type 1 , in which Th1 lymphocytes and M1-polarized macrophages limit tumor progression, and type 2, in which Th2 lymphocytes and M2 macrophages favor immune escape and disease progression [7]. Natural Killer (NK) cells are a subset of lymphocytes that

\footnotetext{
*Correspondence: shiguiyan_zrgk@163.com

1 Department of Orthopedics, 2nd Affiliated Hospital, School of Medicine, Zhejiang University, \#88 Jie Fang Road, 310009 Hangzhou, Zhejiang, People's Republic of China

Full list of author information is available at the end of the article
}

participate in innate immunity. Dendritic cells bridge innate and adaptive immunity and participate in both responses. Tumor-associated macrophages (TAMs) have emerged as promising target for anti-cancer immunotherapy. MDSC block adaptive immunity. Cytotoxic $\mathrm{T}$ cells directed against antigens that are endogenously expressed and presented by cancer cells are critically involved in antigen-specific cancer immunotherapy.

Meanwhile, COX-2 contributes to immune evasion and resistance to cancer immunotherapy. The activity of COX-2 -PGE2-EPs signal pathway can suppress Dendritic cells (DCs), natural killer (NK), T cells, type-1 immunity, but promote type-2 immunity, which promote tumor immune evasion. COX-2 inhibitors may have off-target effects on immune cells and can counterbalance their activity as enhancers of susceptibility to immune elimination. So, COX-2 may serve as predictive biomarker and as therapeutic target for modulation of immune resistance in cancer.

\section{Cyclooxygenase}

The cyclooxygenase (COX) isoenzymes, known as prostaglandin (PG) rate-limiting synthase, catalyze the metabolism of arachidonic acid (AA) to PGs. Finally, a series of biologically active prostaglandins (PGD2, PGE2, 
PGF2 $\alpha$, and PGI2) and thromboxane A2 (TXA2) are formed. There are three isoforms of the enzyme that have been identified: COX-1, COX-2, and COX-3 [8]. Considered as a "housekeeping enzyme", COX-1 is constitutively expressed in human cells. COX-3, an alternate splice variant of COX-1, is most abundant in the canine cerebral cortex. COX-2 is an inducible enzyme and is associated with inflammatory diseases and carcinogenesis, which is suspected to promote angiogenesis and tissue invasion of tumors $[9,10]$ and resistance to apoptosis $[8,11]$. Moreover, COX-2-dependent prostaglandin release can suppress antigen presentation and immune activation in cancer [12]. Therefore, COX-2 and the prostaglandin cascade play important roles in the "inflammogenesis of cancer".

\section{COX-2: $\mathrm{PGE}_{2}$-prostaglandin $\mathrm{E}$ receptors signal pathway}

Arachidonic acid (AA) is transformed into unstable intermediate PGG2, which is promptly converted into PGH2 by cyclooxygenases (COXs) and finally into five primary prostaglandins $\left(\mathrm{PGD}_{2}, \mathrm{PGE}_{2}, \mathrm{PGF}_{2 \alpha}, \mathrm{PGI}_{2}\right.$, and $\left.\mathrm{TXA}_{2}\right)$ by cell-specific synthases. The actions of these prostanoid ligands are mediated by their engagement of specific cellsurface G-protein-coupled receptors designated EP1-4 for PGE2 [13]. It is widely accepted that alterations of cyclooxygenase-2 (COX-2) expression as well as its massive enzymatic product PGE2 play a key role in influencing the development of cancer because their level is found markedly elevated in tissues of cancer [1-6].

Both COX-1 and COX-2 are capable of converting AA into prostaglandins. However, they exhibit preferentially in synthesizing prostaglandins [14]. It has been demonstrated that $\mathrm{PGE}_{2}$ and $\mathrm{PGI}_{2}$ are mainly derived from the COX-2 pathway [15]. PGE2 is generated from $\mathrm{PGH} 2$ by cytosolic PGE2 synthase (cPGES) and membrane-bound microsomal PGE2 synthase-1 and -2 (mPGEs-1 and -2). Once PGE2 is synthesized, it diffuses immediately and activates its specific membrane receptors (EP1-4). EP1 receptors couple with the Gq-phospholipase C(PLC)inositol trisphosphate (IP3) pathway and its activation results in the release of intracellular $\mathrm{Ca} 2+$. EP2 and EP4 receptors couple with the Gs-adenylyl cyclase (AC)cAMP-protein kinase A (PKA) pathway. EP3 couples with a pertussis toxin-sensitive Gi protein to inhibit AC resulting in a decrease in cAMP [15].

Chell et al. [16] report that compared with normal colonic epithelium, protein expression will increased in colorectal cancers $(100 \%)$ as well as adenomas (36 \%) when using immunohistochemistry in vivo EP4 receptor. PGE2 signaling through the EP4 receptor has previously been associated with colorectal tumorigenesis. Fujino $\mathrm{H}$ reported that EP2 receptor mediated activation of Tcf transcriptional activity is primarily through a cAMP/ protein kinase A (PKA) dependent mechanism; whereas, EP4 receptor mediated activation occurs primarily through a phosphatidylinositol 3-kinase (PI3K) dependent pathway [17]. Recently, they have found that PGE2 stimulation of EP4 receptors activates an additional PI3K-dependent pathway leading to the phosphorylation of the extracellular signal-regulated kinases (ERKs), followed by induction of the functional expression of early growth response factor 1 (EGR-1) [18, 19]. ERKs phosphorylation and induction of EGR-1 expression was unique for EP4 receptors and was not observed in cells that expressed EP2 receptors $[18,19]$. Cyclin D1, a key regulator of cell cycle progression, is under the control of EGR-1 through a PI3K- and ERK-dependent pathway [20]. EP4-dependent activation of PI3K/Akt signaling has been reported to stimulate the proliferation and motility of colorectal cancer cells [21]. Therefore, it concerns a possible role for EP4 receptors in cancer.

The role which EP2 receptors played in cancer is still controversial. Sonoshita et al. [22] showed that homozygous deletion of the gene encoding EP2 would cause the decreases in number and size of intestinal polyps in Apc $\Delta 716$ mice (a mouse model for human familial adenomatous polyposis). Homozygous gene knockout for other PGE2 receptors, EP1 or EP3, did not affect the intestinal polyp formation in Apc $\Delta 716$ mice. Fujino et al. [17] suggested that the increased expression of COX-2 via EP2 receptors and an increased expression of PGE2 synthase via EP4 receptors could explain the increased biosynthesis of PGE2 known to occur in colon cancer.

\section{COX-2: $\mathrm{PGE}_{2}$-prostaglandin $\mathrm{E}$ receptors suppress innate and adaptive immunity}

COX-2: PGE2-prostaglandin $\mathrm{E}$ receptors contributes to immune evasion and resistance to cancer immunotherapy (Table 1), which have been reported to augment pro-tumorigenic type 2 lymphocyte [23]. COX-2: PGE2 has been considered as a major product and modulator of activated macrophages [24] for a long time. Tumorassociated macrophages (TAMs) represent a major subpopulation of tumor infiltrating immune cells, which has emerged as a promising target for anti-cancer immunotherapy. Hindering macrophage polarization towards a pro-tumor M2 phenotype, or better still reprogramming the M2 like TAMs towards M1 subtype is being considered a beneficial anti-cancer strategy. COX-2/PGE2 Pathway Promotes M2 Macrophage Differentiation [25, 26]. Macrophage-mediated immune suppression is correlated with increased CD4+ CD25+ regulatory $\mathrm{T}$ cell infiltration and reduced CD8+ cytotoxic $\mathrm{T}$ cell function.

Natural Killer (NK) cells are a subset of lymphocytes that participate in innate immunity. NK cells express all 
Table 1 The role of COX-2 as an oncogene or suppression of tumor immunity

\begin{tabular}{|c|c|}
\hline \multirow[t]{5}{*}{ Oncogene } & Promotes angiogenesis and tissue invasion of tumors $[7,8]$, resistance to apoptosis $[9,10]$ \\
\hline & COX-2-PGE2-Prostaglandin E Receptors signal pathway [12] \\
\hline & PI3K-dependent pathway [16] \\
\hline & Extracellular signal-regulated kinases (ERKs) [17] \\
\hline & Early growth response factor 1 (EGR-1) [18] \\
\hline \multicolumn{2}{|l|}{ Innate immunity } \\
\hline \multirow[t]{2}{*}{ Macrophages } & Augment pro-tumorigenic type 2 lymphocyte [22] \\
\hline & Promotes M2 macrophage differentiation $[24,25]$ \\
\hline \multirow[t]{2}{*}{ Natural Killer (NK) cells } & Inhibits the potential of NK cells to migrate, exert cytotoxic effects, and secrete interferony [26] \\
\hline & $\begin{array}{l}\text { Inhibits major NK receptors (NKR): NKG2D, CD16 and natural cytotoxicity receptors (NCR: NKp30, } \\
\text { NKp44, NKp46) [27] }\end{array}$ \\
\hline \multirow[t]{3}{*}{ Dendritic cells } & A key immunomodulator of DC biology [28] \\
\hline & $\begin{array}{l}\text { Reduces the maturation of DCs and their expression of MHC class II } \\
\text { molecules [29] }\end{array}$ \\
\hline & The production of endogenous IL-10 adaptive immunity \\
\hline \multicolumn{2}{|l|}{ Adaptive immunity } \\
\hline \multirow[t]{3}{*}{$B$ and $T$ cells } & Inhibits proliferation of B and T lymphocytes [31] \\
\hline & $\begin{array}{l}\text { Bluntes the interferon-gamma release of antigen-specific } T \text { cells and increased the expression of } \\
\text { interleukin- } 4 \text { and indoleamine }\end{array}$ \\
\hline & 2,3-dioxygenase by tumor cells [32] \\
\hline ү T cells & Inhibits $\gamma \delta$ T cell receptors TCR Vү9V82, NKG2D, CD16 [27] \\
\hline \multirow[t]{3}{*}{ Tregs } & Induces Tregs [34] \\
\hline & Promotes CD4+ and CD8+ T cells differentiation in Tregs [33] \\
\hline & Inhibits effector T cells in a COX-2-dependent manner $[35,36]$ \\
\hline MDSC & COX-2 would maintain elevated MDSC levels [40] \\
\hline
\end{tabular}

PGE2 EP receptors, and tumor-derived PGE2 represents a major barrier to the success of NK cell mediated killing. PGE2 inhibits the potential of NK cells to migrate, exert cytotoxic effects, and secrete interferony [27]. Martinet et al. [28] also demonstrate that the major NK receptors (NKR): NKG2D, CD16 and natural cytotoxicity receptors (NCR: NKp30, NKp44, NKp46) are all inhibited by PGE2. The ability of PGE2 to inhibit NK cells is by acting on EP2 and EP4 receptors. They also report that a recently described EP4 antagonist, frondoside A, inhibits breast tumor metastasis in an NK-dependent manner and protects IFN $\gamma$ production by NK cells from PGE2 mediated suppression.

Dendritic cells could bridge the innate and adaptive immunity and participate in both responses. COX-2/ PGE2 has become a key immunomodulator of DC biology [29], which can exert inhibitory activity and reduce the maturation of DCs and their expression of MHC class II molecules, ability to present antigen and activate $\mathrm{T}$ cells [30]. Meanwhile, prostaglandin E2 enhances the production of endogenous IL-10, which down-regulates dendritic cell functions. PGE2 modulates dendritic cell function via EP2 and EP4 receptor subtypes. It is suggested that targeting PGE2 EP2/EP4 receptor signaling may be a powerful mechanism for modulating DC activity [31].

Over-expression of COX-2 can initiate and promote carcinogenesis by inhibiting proliferation of $\mathrm{B}$ and $\mathrm{T}$ lymphocytes, particularly natural killer $\mathrm{T}$ cells, thus limiting antineoplastic activity (immunosuppression) [32]. Göbel et al. [33] have identified COX-2-PGE2 as resistance factor against the cytotoxicity induced by activated, antigen-specific T cells. COX-2 expression blunted the interferon-gamma release of antigen-specific $\mathrm{T}$ cells exposed to their respective cellular targets, and increased the expression of interleukin-4 and indoleamine 2,3-dioxygenase by tumor cells.

It has been reported that $\gamma \delta \mathrm{T}$ cell receptors TCR $\mathrm{V} \gamma 9 \mathrm{~V} \delta 2, \mathrm{NKG} 2 \mathrm{D}$ and CD16 are all inhibited by PGE2 [28]. PGE2 also contributes to inhibit directly the proliferation and effector functions of CD4+ and CD8+ T cells and to promote their differentiation in regulatory $\mathrm{T}$ cells [34]. COX-2/PGE(2) induces Tregs, and Treg cells support the cancer-mediated immune suppression. The extent of COX-2 expression was associated significantly with Treg prevalence $(\mathrm{P}=0.004)$ and Treg intratumoral localization $(P=0.005)$ [35]. Several studies have demonstrated that Treg cells contribute to immunosuppression 
in cancer and inhibit effector T cells in a COX-2-dependent manner [36, 37]. The suppressive activity of $\mathrm{T}$ regulatory cells is driven by expression of the forkhead/winged helix transcription factor (FOXP3) gene [38, 39].

MDSC are present in many cancers, which block adaptive immunity by inhibiting the activation of CD4+ and $\mathrm{CD} 8+\mathrm{T}$ cells [40] and innate immunity by inhibiting natural killer cells [41].Once a tumor is established, tumor cell production of COX2 would maintain elevated MDSC levels, further blocking tumor immunity and allowing the malignant cells to proliferate without interference from the host's immune system. This provides a rationale for therapeutic targeting of COX-2 expression and stressinduced prostaglandin synthesis to boost immune surveillance and immunotherapy of cancer.

Above all, COX-2-PGE2- EP2/4 signal pathway plays an important part in the development of cancer; therefore, the EP2/4 receptors may represent an important target for cancer prevention and treatment.

\section{COX-2 inhibitors inhibit immune evasion}

Conventional non-steroidal anti-inflammatory drugs (NSAIDs) and COX-2 selective inhibitors have been demonstrated to overcome tumor immune evasion. It has been suggested that COX-inhibitors may sensitize type 1 immune responses via inhibiting M2 macrophage, T regulatory cells, MDSC; enhancing DC, NK, cytotoxic T-lymphocyte functions [42]. Use of selective COX-2 inhibitors could result in a significant risk reduction for each type of cancer (71 \% for breast cancer, $55 \%$ for prostate cancer, $70 \%$ for colon cancer, and $79 \%$ for lung cancer) and an overall $68 \%$ risk reduction for all four cancers. This investigation demonstrates that COX-2 blocking agents have strong potential for the chemoprevention of cancers [32].

PGE2 inhibits production of the inflammatory chemokines CCL3 and CCL4, which is mediated through EP2 and EP4 receptors, preventing excess accumulation of activated immune cells [43]. Further analysis revealed that COX inhibitors and EP4 receptor antagonism contribute to NK functions critical to the control of metastatic disease. In vivo, NK cells were necessary for the therapeutic effects of COX inhibitors. Further, mammary tumor cells treated with COX inhibitors were more sensitive to NK mediated lysis. Moreover, expression of inhibitory ligands for NK cells were decreased and stimulatory ligands were increased by treatment with COX inhibitors or EP4 receptor antagonists. These studies suggest that EP4, expressed on malignant cells, is a potential therapeutic target $[26,44,45]$.

COX-2 inhibition would cause the loss of the M2 macrophage characteristics of TAMs and may assist prevention of breast cancer metastasis. Chen et al. [46] suggest that inhibition of myeloid cell COX-2 can potentiate CTL-mediated tumor cytotoxicity and may provide a novel therapeutic approach in breast cancer therapy. They found that the specific COX-2 inhibitor, inhibited human M2 macrophage differentiation, as determined by decreased CD14 and CD163 expressions and increased TNFY production. At the same time, COX-2 inhibition alters the phenotype of tumor-associated macrophages from M2 to M1 in ApcMin/+ mouse polyps.

Meanwhile, COX-2 inhibition potentiates macrophage's inflammatory cytokine responses but reduces IL-10 secretion thus might skew overall tumor microenvironment to favor Th1 immune responses which was confirmed by reduced regulatory $\mathrm{T}$ cells as well as myeloid derived suppressor cells in etodolac fed mice tumor mass [45]. COX-2 KO mice resulted from disruption of M2-like TAM function, and thereby enhancing $\mathrm{T}$ cell survival and immune surveillance [46]. PGE2 seems to influence the antigen-specific cellular responses of both $\mathrm{T}$ cells and APCs because reversal of inhibition was seen by pretreatment of both with COX-2 inhibitor. COX-2 inhibitor attenuates Treg cell activity and Foxp3 expression in tumor-infiltrating lymphocytes and enhances antitumor responses [47, 48], which still delays primary tumor growth and reduces MDSC accumulation [49].

Meta-analysis of independent estimates from 72 studies provides no evidence that the selective COX-2 inhibitor will influence the relative risk of cardiovascular disease (composite relative risk $=0.98,95 \% \mathrm{CI}=0.88-1.10$ ) [50]. Meanwhile, the mechanisms of COX-2 inhibitors regulate the tumor immune evasion still needs further research.

\section{Conclusion}

In this review, we have tried to encompass the role of COX-2 in the regulation of tumor immune evasion. The activity of COX-2 is suspected to promote angiogenesis, tissue invasion of tumors and resistance to apoptosis and chemotherapy. The activity of COX-2-PGE2-Prostaglandin E Receptors signal pathway can suppress Dendritic cells (DCs), natural killer (NK), T cells, type-1 immunity, but promote type- 2 immunity, which promote tumor immune evasion. COX-2 and the prostaglandin cascade play an important part in the "inflammogenesis of cancer". In addition, COX-inhibitors can inhibit tumor immune evasion. Therefore, we can exert the COX-inhibitors benefit from addition of COX-inhibitors to standard cytotoxic therapy, which can overcome tumor immune evasion.

\section{Authors' contributions}

All of authors carried out reading the literature and drafting the manuscript. All authors read and approved the final manuscript. 


\section{Author details}

${ }^{1}$ Department of Orthopedics, 2nd Affiliated Hospital, School of Medicine, Zhejiang University, \#88 Jie Fang Road, 310009 Hangzhou, Zhejiang, People's Republic of China. ${ }^{2}$ Clinical Laboratory Centre, 2nd Affiliated Hospital, School of Medicine, Zhejiang University, \#88 Jie Fang Road, 310009 Hangzhou, Zhejiang, People's Republic of China. ${ }^{3}$ Clinical Laboratory Centre, Binjiang Hospital of Hangzhou, Hangzhou, Zhejiang, People's Republic of China.

\section{Competing interests}

The authors declare that they have no competing interests.

Received: 18 July 2015 Accepted: 28 October 2015

Published online: 05 November 2015

\section{References}

1. Eberhart CE, Coffey RJ, Radhika A, Giardiello FM, Ferrenbach S, DuBois RN. Up-regulation of cyclooxygenase 2 gene expression in human colorectal adenomas and adenocarcinomas. Gastroenterology. 1994;107:1183-8.

2. Koga H, Sakisaka S, Ohishi M, Kawaguchi T, Taniguchi E, Sasatomi K, Harada M, Kusaba T, Tanaka M, Kimura R, Nakashima Y, Nakashima O, Kojiro M, Kurohiji T, Sata M. Expression of cyclooxygenase-2 in human hepatocellular carcinoma: relevance to tumor dedifferentiation. Hepatology. 1999;29:688-96.

3. Tucker ON, Dannenberg AJ, Yang EK, Zhang F, Teng L, Daly JM, Soslow RA, Masferrer JL, Woerner BM, Koki AT, Fahey TJ 3rd. Cyclooxygenase-2 expression is up-regulated in human pancreatic cancer. Cancer Res. 1999;59:987-90

4. Hwang D, Scollard D, Byrne J, Levine E. Expression of cyclooxygenase-1 and cyclooxygenase-2 in human breast cancer. J Natl Cancer Inst. 1998;90:445-60.

5. Hida T, Yatabe Y, Achiwa H, Muramatsu H, Kozaki K, Nakamura S, Ogawa M, Mitsudomi T, Sugiura T, Takahashi T. Increased expression of cyclooxygenase 2 occurs frequently in human lung cancers, specifically in adenocarcinomas. Cancer Res. 1998;58:3761-4.

6. DeNardo DG, Andreu P, Coussens LM. Interactions between lymphocytes and myeloid cells regulate pro- versus anti-tumor immunity. Cancer Metastasis Rev. 2010;29:309-16.

7. Tsujii M, Kawano S, DuBois RN. Cyclooxygenase-2 expression in human colon cancer cells increases metastatic potential. Proc Natl Acad Sci. 1997;94:3336-40.

8. Sharma S, Stolina M, Yang SC, Baratelli F, Lin JF, Atianzar K, et al. Tumor cyclooxygenase 2-dependent suppression of dendritic cell function. Clin Cancer Res. 2003;9:961-8.

9. Tsujii M, Kawano S, Tsuji S, Saeaoka H, Hori M, DuBois RN. Cyclooxygenase regulates angiogenesis induced by colon cancer cells. Cell. 1998;93:705-16.

10. Tsujii M, DuBois RN. Alterations in cellular adhesions and apoptosis in epithelial cells overexpressing prostaglandin endoperoxidase synthase 2. Cell. 1995;83:493-501.

11. Nzeako UC, Guicciardi ME, Yoon JH, Bronk SF, Gores GJ. COX-2 inhibits Fas-mediate apoptosis in cholangiocarcinoma cells. Hepatology. 2002;35:552-9.

12. Greenhough A, Smartt HJ, Moore AE, et al. The COX-2/PGE2 pathway: key roles in the hallmarks of cancer and adaptation to the tumour microenvironment. Carcinogenesis. 2009;30:377-86.

13. Yang $\mathrm{H}$, Chen $\mathrm{C}$. Cyclooxygenase-2 in synaptic signaling. Curr Pharm Des. 2008;14:1443-51.

14. Brock TG, McNish RW, Peters-Golden M. Arachidonic acid is preferentially metabolized by cyclooxygenase-2 to prostacyclin and prostaglandin E2. J Biol Chem. 1999;274:11660-6.

15. Chell SD, Witherden IR, Dobson RR, Moorghen M, Herman AA, Qualtrough D, Williams AC, Paraskeva C. Increased EP4 receptor expression in colorectal cancer progression promotes cell growth and anchorage independence. Cancer Res. 2006;15(66):3106-13.

16. Fujino H, West KA, Regan JW. Phosphorylation of glycogen synthase kinase-3 and stimulation of T-cell factor signaling following activation of EP2 and EP4 prostanoid receptors by prostaglandin E2. J Biol Chem. 2002;277:2614-9.
17. Fujino $\mathrm{H}, \mathrm{Xu}$ W, Regan JW. Prostaglandin E2 induction of early growth response factor- 1 by EP4, but not EP2, prostanoid receptors via phosphatidylinositol 3-kinase and the extracellular signal-regulated kinases. J Biol Chem. 2003;278:12151-6.

18. Fujino H, Regan JW. Prostanoid receptors and phosphatidylinositol 3-kinase: a pathway to cancer. Trends Pharmacol Sci. 2003;24:335-40.

19. Guillemot L, Levy A, Raymondjean M, Rothhut B. Angiotensin I-induced transcriptional activation of the cyclin D1 gene is mediated by Egr-1 in CHO-AT(1A) cells. J Biol Chem. 2001;276:39394-403.

20. Sheng $H$, Shao J, Washington MK, DuBois RN. Prostaglandin $E_{2}$ increases growth and motility of colorectal carcinoma cells. J Biol Chem. 2001;276:18075-81.

21. Sonoshita M, Takaku K, Sasaki N, et al. Acceleration of intestinal polyposis through prostaglandin receptor EP2 in Apc $\triangle 716$ knockout mice. Nat Med. 2001;7:1048-51.

22. Eruslanov E, Daurkin I, Ortiz J, Vieweg J, Kusmartsev S. Pivotal advance: tumor-mediated induction of myeloid-derived suppressor cells and M2-polarized macrophages by altering intracellular PGE2 catabolism in myeloid cells. J Leukoc Biol. 2010;88:839-48.

23. Phipps RP, Stein $\mathrm{SH}$, Roper RL. A new view of prostaglandin E regulation of the immune response. Immunol Today. 1991;12:349-52.

24. Li Q, Liu L, Zhang Q, Liu S, Ge D, You Z. Interleukin-17 indirectly promotes M2 macrophage differentiation through stimulation of COX-2/PGE2 pathway in the cancer cells. Cancer Res Treat. 2014;46(3):297-306.

25. Dubey P, Shrivastava R, Tripathi C, Jain NK, Tewari BN, Lone MU, Baghel KS, Kumar V, Misra S, Bhadauria S, Bhatt ML. Cyclooxygenase-2 inhibition attenuates hypoxic cancer cells induced M2-polarization of macrophages. Cell Mol Biol (Noisy-le-grand). 2014;60(3):10-5.

26. Holt DH, Ma X, Kundu N, Fulton AM. Prostaglandin E2 suppresses natural killer cell function primarily through the PGE2 receptor EP4. Cancer Immunol Immunother. 2011;60:1577-86.

27. Martinet L, Jean C, Dietrich D, Fournié JJ, Poupot R. PGE2 inhibits natural killer and gamma delta T cell cytotoxicity triggered by NKR and TCR through a CAMP-mediated PKA type I-dependent signaling. Biochem Pharmacol. 2010;15:838-45.

28. Gualde N, Harizi H. Prostanoids and their receptors that modulate dendritic cell-mediated immunity. Immunol Cell Biol. 2004;82:353-60.

29. Harizi H, Juzan M, Pitard V, Moreau JF, Gualde N. Cyclooxygenase-2-issued prostaglandin E2 enhances the production of endogenous IL-10, which down-regulates dendritic cell functions. J Immunol. 2002;168:2255-63.

30. Harizi H, Grosset C, Gualde N. Prostaglandin E2 modulates dendritic cell function via EP2 and EP4 receptor subtypes. J Leukoc Biol. 2003;73:756-63.

31. Harris RE, Beebe-Donk J, Alshafie GA. Cancer chemoprevention by cyclooxygenase 2 blockade: results of case control studies. Subcell Biochem. 2007:42:193-212.

32. Göbel C, Breitenbuecher F, Kalkavan H, Hähnel PS, Kasper S, Hoffarth S, Merches K, Schild H, Lang KS, Schuler M. Functional expression cloning identifies COX-2 as a suppressor of antigen-specific cancer immunity. Cell Death Dis. 2014;11(5):e1568.

33. Okano M, Sugata Y, Fujiwara T, Matsumoto R, Nishibori M, Shimizu K, Maeda M, Kimura Y, Kariya S, Hattori H, Yokoyama M, Kino K, Nishizaki KE. Prostanoid 2 (EP2)/EP4-mediated suppression of antigen-specific human T-cell responses by prostaglandin E2. Immunology. 2006;1 18(3):343-52.

34. Mougiakakos D, Johansson CC, Trocme E, All-Ericsson C, Economou MA, Larsson O, Seregard S, Kiessling R. Intratumoral forkhead box P3-positive regulatory $T$ cells predict poor survival in cyclooxygenase-2-positive uveal melanoma. Cancer. 2010;116(9):2224-33.

35. Mahic M, Yaqub S, Johansson CC, Taskén K, Aandahl EM. FOXP3+CD4+CD25+ adaptive regulatory $T$ cells express cyclooxygenase-2 and suppress effector T cells by a prostaglandin E2-dependent mechanism. J Immunol. 2006;177(1):246-54.

36. Yuan XL, Chen L, Li MX, Dong P, Xue J, Wang J, Zhang TT, Wang XA, Zhang FM, Ge HL, Shen LS, Xu D. Elevated expression of Foxp3 in tumorinfiltrating Treg cells suppresses T-cell proliferation and contributes to gastric cancer progression in a COX-2-dependent manner. Clin Immunol. 2010;134(3):277-88

37. Hori S, Nomura T, Sakaguchi S. Control of regulatory T cell development by the transcription factor Foxp3. Science. 2003;299:1057-61. 
38. Fontenot JD, Gavin MA, Rudensky AY. Foxp3 programs the development and function of CD4 + CD25 + regulatory T cells. Nat Immunol. 2003:4:330-6

39. Sinha P, Clements VK, Ostrand-Rosenberg S. Reduction of myeloidderived suppressor cells and induction of M1 macrophages facilitate the rejection of established metastatic disease. J Immunol. 2005;174:636-45.

40. Suzuki E, Kapoor V, Jassar AS, Kaiser LR, Albelda SM. Gemcitabine selectively eliminates splenic Gr-1+/CD11b+ myeloid suppressor cells in tumor-bearing animals and enhances antitumor immune activity. Clin Cancer Res. 2005;11:6713-21.

41. Markosyan N, Chen EP, Ndong VN, Yao Y, Sterner CJ, Chodosh LA Lawson JA, Fitzgerald GA, Smyth EM. Deletion of cyclooxygenase 2 in mouse mammary epithelial cells delays breast cancer onset through augmentation of type $1 \mathrm{immune}$ responses in tumors. Carcinogenesis. 2011;32(10):1441-9.

42. Jing $H$, Vassiliou E, Ganea D. Prostaglandin E2 inhibits production of the inflammatory chemokines CCL3 and CCL4 in dendritic cells. J Leukoc Biol. 2003;74:868-79.

43. Kundu N, Ma X, Holt D, Goloubeva O, Ostrand-Rosenberg S, Fulton AM. Antagonism of the prostaglandin E receptor EP4 inhibits metastasis and enhances NK function. Breast Cancer Res Treat. 2009;117(2):235-42.

44. Kundu N, Walser TC, Ma X, Fulton AM. Cyclooxygenase inhibitors modulate NK activities that control metastatic disease. Cancer Immunol Immunother. 2005:54(10):981-7.
45. Chen EP, Markosyan N, Connolly E, Lawson JA, Li X, Grant GR, Grosser T, FitzGerald GA, Smyth EM. Myeloid Cell COX-2 deletion reduces mammary tumor growth through enhanced cytotoxic T-lymphocyte function. Carcinogenesis. 2014;35(8):1788-97.

46. Na YR, Yoon YN, Son DI, Seok SH. Cyclooxygenase-2 inhibition blocks M2 macrophage differentiation and suppresses metastasis in murine breast cancer model. PLoS One. 2013;8(5):e63451.

47. Sahin M, Sahin E, Koksoy S. Regulatory T cells in cancer: an overview and perspectives on cyclooxygenase-2 and Foxp3 DNA methylation. Hum Immunol. 2013;74(9):1061-8.

48. Sharma S, Yang SC, Zhu L, Reckamp K, Gardner B, Baratelli F, Huang M, Batra RK, Dubinett SM. Tumor cyclooxygenase-2/prostaglandin E2-dependent promotion of FOXP3 expression and CD4 + CD25 + T regulatory cell activities in lung cancer. Cancer Res. 2005;65(12):5211-20.

49. Sinha P, Clements VK, Fulton AM, Ostrand-Rosenberg S. Prostaglandin E2 promotes tumor progression by inducing myeloid-derived suppressor cells. Cancer Res. 2007;67(9):4507-13.

50. Harris RE. Cyclooxygenase-2 (cox-2) blockade in the chemoprevention of cancers of the colon, breast, prostate, and lung. Inflammopharmacology. 2009;17(2):55-67.

\section{Submit your next manuscript to BioMed Central and take full advantage of:}

- Convenient online submission

- Thorough peer review

- No space constraints or color figure charges

- Immediate publication on acceptance

- Inclusion in PubMed, CAS, Scopus and Google Scholar

- Research which is freely available for redistribution

Submit your manuscript at

www.biomedcentral.com/submit

() Biomed Central 